\title{
ANALYSIS OF THE DIAGNOSTIC POTENTIAL RESEARCH THERMOVISION IN THE TECHNICAL STATE OF COMBUSTION ENGINE INJECTORS ASSESSMENT
}

\author{
T. Kalaczyński ${ }^{*}$, M. Lukasiewicz ${ }^{* *}$, J. Musial $^{* * *}$, R. Polasik ${ }^{\dagger}$, M. Szczutkowski $^{\ddagger}$, \\ N. Dluhunovych ${ }^{\ddagger \ddagger}$, J. Wilczarska ${ }^{\S}$, T. Kasprowicz ${ }^{\S \S}$
}

\begin{abstract}
The paper presents an analysis of research thermographic implementing possibilities in the technical state of internal combustion engine injectors assessment. The presented method is an innovative approach to diagnosing the injectors state used in internal combustion engines. The discussed non-installation method of assessment injectors technical state uses measurements of accompanying processes such as heat generation by their working elements. The use of thermovision cameras allows direct verification of the injectors state. This will allow reducing the time of locating the injector malfunctions which will significantly increase the efficiency of the diagnostics process. That while also assessing the impact of damage on the internal combustion engine operating parameters.
\end{abstract}

Keywords: technical state, diagnostics, thermovision, injector, fuel supply system

\section{Introduction}

Constructors of internal combustion engines used in modern motor vehicles have the task to achieve an optimal balance between the operating parameters, work economics and the impact of combustion engines on the environment (Kałaczyński T. et al., 2014). Rigorous emission standards to modern engines are subjected they generate new construction solutions or modify existing ones. Undoubtedly, the combustion process of the fuel and air mixture is fulfilling the expectations and environmental requirements. Ensuring quantitative and qualitative homogeneity is one of the tasks of fuel supply systems. The important link contributing to the realization of this task is the technical state of the actuators in fuel supply systems. The main elements of the power systems are injectors, their technical state affects the execution of work processes and thus for implementation assumptions for internal combustion engines.

Tomasz Kałaczyński, PhD.: Faculty of Mechanical Engineering, University of Science and Technology, Al. prof. S. Kaliskiego 7, Bydgoszcz; PL, kalaczynskit@utp.edu.pl.

** Marcin Łukasiewicz, PhD.: Faculty of Mechanical Engineering, University of Science and Technology, Al. prof. S. Kaliskiego 7, Bydgoszcz; PL, mlukas@utp.edu.pl.

*** Prof. Janusz Musiał, PhD.: Faculty of Mechanical Engineering, University of Science and Technology, Al. prof. S. Kaliskiego 7, Bydgoszcz; PL, jamusual@utp.edu.pl

† Robert Polasik, PhD.: Faculty of Mechanical Engineering, University of Science and Technology, Al. prof. S. Kaliskiego 7, Bydgoszcz; PL, robpol@utp.edu.pl.

‡ Marek Szczutkowski, PhD.: Faculty of Mechanical Engineering, University of Science and Technology, Al. prof. S. Kaliskiego 7, Bydgoszcz; PL, m.szczutkowski@utp.edu.pl.

㚘 Natalia Dluhunovych, PhD: Faculty of Programming, Computer and Telecommunication Systems, Khmelnytsky National University, Instytutska str. 11, Khmelnytskiy, 29016, Ukraine, dlugunovich@gmail.com

$\S$ Joanna Wilczarska, PhD.: Faculty of Mechanical Engineering, University of Science and Technology, Al. prof. S. Kaliskiego 7, Bydgoszcz; PL, joanna.wilczarska@utp.edu.pl.

$\S \S$ Tomasz Kasprowicz, M.Sc.: Faculty of Mechanical Engineering, University of Science and Technology, Al. prof. S. Kaliskiego 7, Bydgoszcz; PL, kasprowicz.tomasz@gmail.com 
Attention should also be paid to the problem of internal combustion engines diagnostic susceptibility and the difficult process of dismantling their elements. In connection with the above, there is a necessity to propose a method for assessment the injectors technical state, which would allow the implementation of a non-detachable diagnostic procedure. One of the group of non-editing methods assessment of technical object state there are thermovision research. This method uses a special type of television that records the heat emitted by objects in its field of view, and more specifically - the emission of infrared radiation. Measuring the infrared radiation sent by a given body, we measure its temperature (Więcek B., 2010). The diagnostic potential of thermographic research should be assessed in assessment the injectors technical state of internal combustion engines.

\section{Methods}

Fuel supply systems fulfill a lot of functions in the engine that determine the mixture and emission of exhaust gases, which generates the need to monitor the elements state. In addition, there are many variants of the design of supply units and their placement locations (Landowski et al., 2017, Łukasiewicz et al., 2013).

The this work focuses on the evaluation of the technical state of electromagnetic injectors used in internal combustion engines. In electromagnetic injectors the control current flowing in the coil generates a magnetic field, which pulls the anchors into the coil, beating the resistance of the spring and lifting the nozzles of the opening sprayer fuel flow through a channel located in the needle seat (Heiko P., 2016).

The injectors were subjected to thermovision research, which enabled a non-assembly assessment of the technical condition. The tests were carried out at a stationary stand shown in Figure 1, which allowed for the implementation of the procedure dedicated to the injectors.
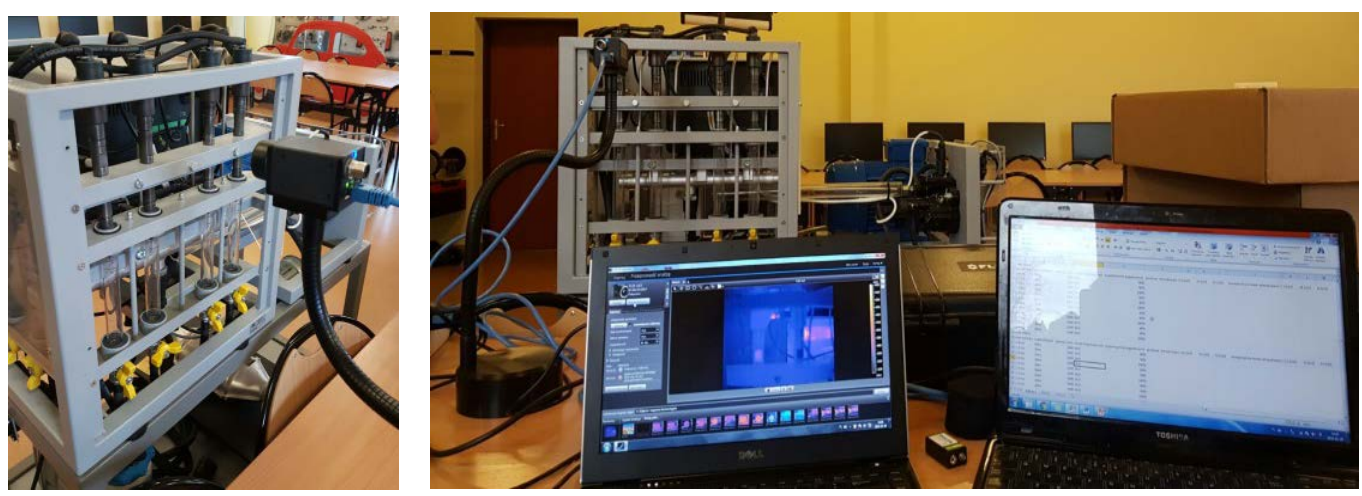

Fig. 1: Test stand

The test stand is equipped with electromagnetic injectors used in the Alfa Romeo 156, 2.4 JTD engine (Figure 2a), FLIR I5 stationary thermographic camera shown on (Figure 2b), FLIR Ax / Ax5 series thermographic camera (Figure 2c)
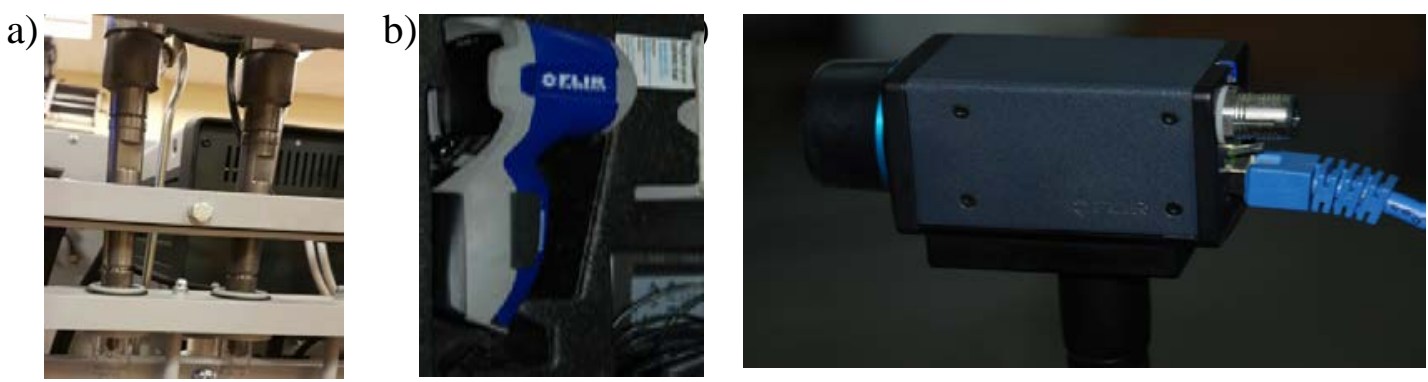

Fig. 2: Equipment test stand

Based on the preliminary tests, the test conditions have been established:

- Ambient temperature - $25^{\circ} \mathrm{C}$

- Measuring distance - $30 \mathrm{~cm}$

- Rotational speed - 1500 rpm

- Injection frequency - $30 \mathrm{~Hz}$

- injection duration - $2.0 \mathrm{~ms}$ 
The tests were performed in three series of measurements lasting 5 minutes at 4 measuring points whose distribution is shown in Figure 3.

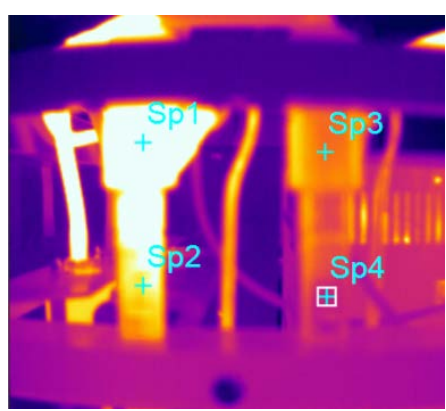

Fig. 3: Locations of measurement points

The measurement results of the temperature distribution shown in Table 1

Tab. 1: Temperature measurement results

\begin{tabular}{|c|c|c|c|c|c|c|c|c|c|c|c|c|c|c|c|c|c|c|c|c|}
\hline \multicolumn{7}{|c|}{ series I } & \multicolumn{7}{|c|}{ series II } & \multicolumn{7}{|c|}{ series III } \\
\hline \multicolumn{21}{|c|}{ camera FLIR I5 } \\
\hline $\begin{array}{l}\text { Time } \\
(\mathrm{min})\end{array}$ & 0 & 1 & 2 & 3 & 4 & 5 & $\begin{array}{l}\text { Time } \\
(\mathrm{min})\end{array}$ & 0 & 1 & 2 & 3 & 4 & 5 & $\begin{array}{l}\text { Time } \\
\text { (min) }\end{array}$ & 0 & 1 & 2 & 3 & 4 & 5 \\
\hline \multicolumn{7}{|c|}{ measuring point } & \multicolumn{7}{|c|}{ measuring point } & \multicolumn{7}{|c|}{ measuring point } \\
\hline 1 & 27,8 & 43 & 51 & 57 & 61 & 63 & 1 & 27,8 & 47,7 & 51,3 & 59 & 59 & 63 & 1 & 24,3 & 48 & 55 & 59 & 62 & 69 \\
\hline II & 27,7 & 30 & 40 & 41 & 45 & 45,6 & II & 27,7 & 35 & 38 & 42 & 42 & 45 & II & 24,2 & 36 & 38 & 38 & 40 & 42 \\
\hline III & 28,1 & 30 & 34 & 38 & 41 & 43 & III & 28,1 & 32,8 & 35 & 36 & 40 & 42 & III & 24,4 & 37 & 40 & 43 & 46 & 50 \\
\hline IV & 27,5 & 27 & 33 & 35 & 34 & 35 & IV & 27,5 & 29,2 & 30 & 31 & 32 & 34 & IV & 24,2 & 31 & 35 & 38 & 40 & 44 \\
\hline \multicolumn{21}{|c|}{ pyrometer } \\
\hline 1 & 24,9 & 30 & 40 & 45 & 51 & 50 & I & 24,6 & 39 & 42 & 43 & 43 & 43 & 1 & 24,1 & 34 & 38 & 44 & 46 & 47 \\
\hline II & 24,9 & 25 & 28 & 34 & 36 & 36 & II & 24,5 & 27 & 37 & 38 & 39 & 39 & II & 24,1 & 26 & 29 & 32 & 32 & 35 \\
\hline III & 25,2 & 28 & 32 & 37 & 36 & 38 & III & 24,9 & 29 & 31 & 32 & 35 & 36 & III & 24,2 & 31 & 35 & 37 & 42 & 45 \\
\hline IV & 25,1 & 25 & 28 & 31 & 34 & 36 & IV & 24,7 & 27 & 28 & 29 & 30 & 32 & IV & 24,3 & 28 & 27 & 31 & 32 & 40 \\
\hline \multicolumn{21}{|c|}{ camera FLIR $\mathrm{Ax} / \mathrm{Ax} 5$ series } \\
\hline 1 & 31,7 & 35,4 & 37,7 & 39 & 40,1 & 41,09 & 1 & 32,6 & 42,4 & 47,8 & 50 & 51,7 & 53,4 & 1 & 33,3 & 41,7 & 46,1 & 49,3 & 51,1 & 52,6 \\
\hline II & 32,7 & 33,3 & 34,2 & 35 & 35,4 & 35,9 & II & 32,2 & 34,4 & 37,3 & 39,1 & 40,3 & 41,5 & II & 32 & 32,7 & 36,4 & 38,6 & 39,9 & 41,2 \\
\hline III & 31,9 & 32,3 & 33 & 33 & 33,9 & 34,2 & III & 32,3 & 33,1 & 34,4 & 35,2 & 36,2 & 37,3 & III & 32,6 & 35,5 & 37,3 & 39,4 & 41,3 & 43,3 \\
\hline IV & 31,7 & 31,6 & 31,4 & 31 & 32 & 32,2 & IV & 31,5 & 32,7 & 33,4 & 33,6 & 34,2 & 35 & IV & 32,7 & 33,6 & 35,2 & 36,9 & 39 & 39,5 \\
\hline
\end{tabular}

The analysis of the obtained results allows to determine the accuracy of the measuring device as well as to verify the dependence of the increase in the temperature gradient at the measuring points. The test results presented in the table are measurements at selected points using different measurement methods. More detailed analysis requires propagation of the thermal energy flow in the injector based on the analysis of thermographic images. FLIR Tools software was used to analyze thermographic images.

Figure 4 presents selected test results obtained using the FLIR I5 thermographic camera. In contrast, Figure 5 presents the results obtained with the FLIR AX / AX5 thermographic camera.

To confirm the obtained results it is necessary to check the electromagnetic injectors through measuring the resistance of the solenoid valve coil on both contacts of its connector socket (Fig. 6a). Injector verification confirmed damage to the coil as shown in Figure 6b. 

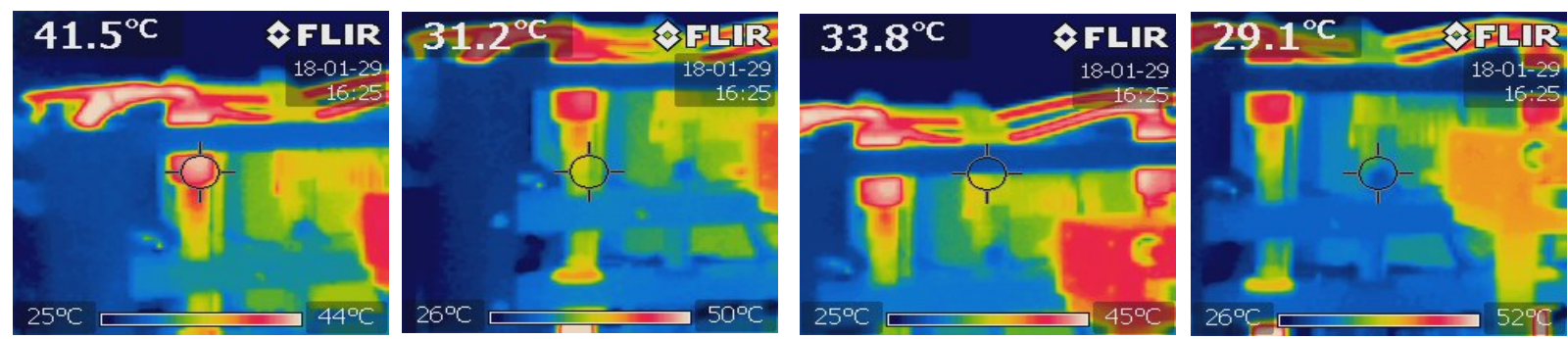

Fig. 4: Selected test results for the FLIR I5 thermovision camera

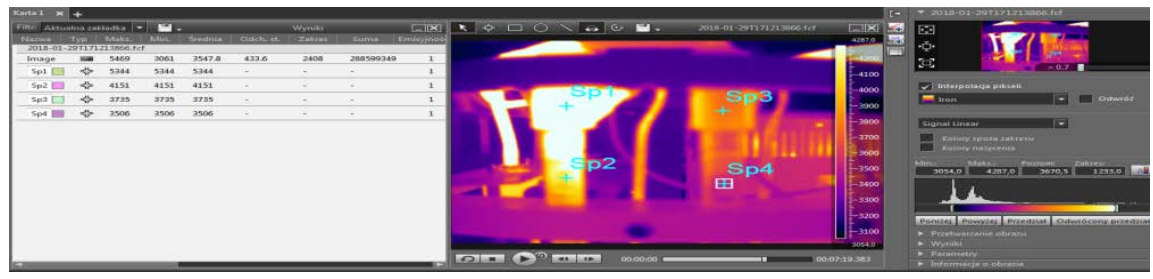

Fig. 5: Selected test results for the FLIR AX/AX5 thermovision camera

a)

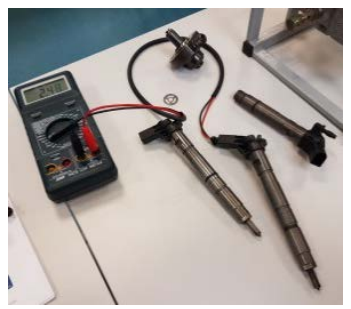

b)

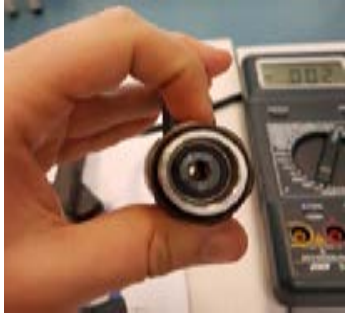

Fig. 6: Verification of damage to the injector

The paper presents the process of injectors technical state verification by using thermographic tests, which underwent verification confirming the results of the conducted research.

\section{Conclusions}

The development of the fuel supply systems construction for internal combustion engines indicates the problem of service and diagnostics. In this connection with the above, we need to implement innovative methods for assessment the technical state of power systems in fuel based on a non-installation diagnostic procedure. One of the variants is thermovision methods in the diagnosis of these elements. This process is not easy to implement due to the high sensitivity of detectors and the influence of external factors.

Additionally, the process of acquisition and validation of measurement data correlation with the state of technical object requires experience and knowledge from the person performing the diagnostic procedure.

\section{References}

Heiko P., (2016) Układy bezpośredniego wtrysku benzyny w praktyce warsztatowej, wydawnictwo Komunikacji i Łączności, Warszawa

Kałaczyński T., Łukasiewicz M., Kasprowicz T, Liss M. (2014) The use of thermographic image analysis in the assessment of brake system. 13th International Technical System Degradation Conference Liptovsky Mikulas, pp. 126-128.

Landowski B., Pająk M., Żółtowski B., Muślewski Ł. (2017) Method of building a model of operational changes for the marine combustion engine describing the impact of the damages of this engine on the characteristics of its operation process. Polish Maritime Research 2017, nr 4 (96), vol. 24; pp. 67-76.

Łukasiewicz M., Kałaczyński T., Kasprowicz T, Liss M. (2013) The exploited machine engines technical state assessment with aplicability of LMS Virtual.Lab, V Ukrainian-Polish Scientific Dialogues KhmielnytskyYaremche 2013, pp. 237-243.

Więcek B. (2010) Wybrane zagadnienia współczesnej termowizji w podczerwieni. Politechnika Łódzka, ISBN 9788372833440. 